\title{
METODOLOGIAS ATIVAS E ENSINO HÍBRIDO NA ENGENHARIA: RELATO DE EXPERIÊNCIA
}

\author{
FRANCA/SP MAIO/2018
}

\begin{abstract}
FABIANA PARPINELLI GONÇALVES FERNANDES - UNIFRAN - fabiana.fernandes@unifran.edu.br CARMEN LÚCIA TOZZI MENDONÇA CONTI - UNIFRAN - carmen.conti@unifran.edu.br CARLOS FERNANDO DE ARAÚJO JR - UNICSUL - carlos.araujo@cruzeirodosul.edu.br
\end{abstract}

\author{
Tipo: Relato de Experiência Inovadora (EI) \\ Categoria: Pesquisa e Avaliação \\ Setor Educacional: EDUCAÇÃO SUPERIOR
}

\begin{abstract}
RESUMO
As Instituições de Ensino Superior, preocupadas com a formação do aluno e com sua inserção no mercado de trabalho, precisaram desenvolver mecanismos capazes de minimizar os impactos existentes entre o conhecimento prévio dos alunos que ingressam no ensino superior e as estruturas curriculares dos cursos de graduação. São os chamados, Programas de Nivelamento, uma Política de Atendimento ao Discente como estímulo à permanência orientada pelo Ministério de Educação (MEC) através do artigo 16 do Decreto no 5.773 de 09 de maio de 2006 (MEC, 2006, n.p.). Consoante ao disposto, pretende-se neste trabalho relatar - por meio de uma pesquisa quantitativa-qualitativa - os resultados obtidos na aplicação de um curso gratuito de Nivelamento On-line em Língua Portuguesa oferecido semestralmente aos alunos dos cursos presenciais das Engenharias (Elétrica, Mecânica, Mecatrônica, Civil e Produção) da Universidade de Franca desde o segundo semestre de 2015 via Plataforma Blackboard. Por meio do ensino híbrido aplicado à graduação presencial, os alunos das engenharias participaram ativamente da construção do conhecimento necessário para preencher as lacunas da Língua Portuguesa e acompanhar com bom desempenho as exigências do seu curso superior e do mercado de trabalho, alcançando, assim, a individualização do próprio ensino.
\end{abstract}

Palavras-chave: Ensino híbrido; metodologias ativas; sala de aula invertida; engenharias; língua portuguesa. 


\section{Introdução}

No segundo semestre do ano de 2015, em uma parceria entre a Universidade de Franca (UNIFRAN) e a Universidade Cruzeiro do Sul Educacional Campus Virtual, foi criado um grupo de pesquisadores com o intuito de intensificar o uso de metodologias ativas nos cursos presenciais da UNIFRAN. Intitulado, Tecnologias Digitais no Ensino Superior, o grupo é formado por 5 professores-pesquisadores que atuam em diferentes áreas do conhecimento e 2 coordenadores representantes das duas instituições envolvidas.

Entre os assuntos pesquisados e aplicados pelo grupo nos cursos presenciais da UNIFRAN estão: Problem Based Learning e Project Based Learning (Aprendizagem Baseada em Problemas/Projetos), Flipped Classroom (Sala de Aula Invertida), Peer Instructions (Instrução por Pares) e Blended Learning (Ensino Híbrido).

Como fruto de uma das práticas desenvolvidas por um dos pesquisadores do grupo encontra-se o projeto Nivelamento On-line em Língua Portuguesa - um curso on-line gratuito em Língua Portuguesa ministrado nas engenharias presenciais da UNIFRAN em 4 fases distintas.

O nivelamento on-line foi desenvolvido a partir da metodologia ativa de Sala de Aula Invertida (Flipped Classroom) via Ensino Híbrido (Blended Learning), portanto, temos aqui as metodologias ativas favorecendo novas possibilidades de ensino e aprendizagem condizentes com o paradigma da Era Digital em que vivemos.

Consoante ao exposto, este trabalho tem por objetivo relatar - por meio de uma pesquisa quantitativa-qualitativa - os resultados obtidos na aplicação de metodologia ativa (sala de aula invertida via ensino híbrido) em um curso gratuito de Nivelamento Online em Língua Portuguesa oferecido semestralmente aos alunos dos cursos presenciais das Engenharias (Elétrica, Mecânica, Mecatrônica, Civil e Produção) da Universidade de Franca desde o segundo semestre de 2015.

Os resultados obtidos neste projeto fornecem fonte de referência para pesquisas sobre educação a distância, ensino híbrido, metodologias ativas e ensino de língua portuguesa, integrando conhecimentos em diferentes áreas do saber. 


\section{Objetivos}

Pretende-se neste trabalho relatar - por meio de uma pesquisa quantitativa-qualitativa os resultados obtidos na aplicação de um curso gratuito de Nivelamento On-line em Língua Portuguesa oferecido semestralmente aos alunos dos cursos presenciais das Engenharias (Elétrica, Mecânica, Mecatrônica, Civil e Produção) da Universidade de Franca desde o segundo semestre de 2015 via Plataforma Blackboard.

O Nivelamento On-line em Língua Portuguesa tem por objetivos: Levar o uso das metodologias ativas via ensino híbrido aos cursos presenciais de Engenharia da Universidade de Franca (UNIFRAN); Possibilitar a utilização de novas ferramentas de diagnóstico que apontem para o conhecimento e capital cultural/bagagem do aluno e posterior trabalho na área de desenvolvimento proximal do mesmo (nivelamento); Registrar todo o processo e criar ambiente favorável para pesquisa e publicação dos resultados; Promover maior conhecimento do funcionamento da Língua Portuguesa (leitura, escrita, regras gramaticais e norma culta) visando colaborar com o processo de leitura e produção de textos acadêmicos; Mapear as defasagens de uso da Língua Portuguesa dos alunos das engenharias presenciais.

\section{Referencial Teórico}

A fundamentação teórica centrou-se nos conceitos sobre ensino híbrido (BACICH \& MORÁN, 2015), aprendizagem ativa (VALENTE, 2014), metodologias ativas (MORÁN, 2015) e nativos digitais (PRENSKY, 2001).

\section{Procedimentos Metodológicos}

Para o desenvolvimento do Nivelamento On-line em Língua Portuguesa, em sua primeira fase, foram avaliados os materiais em EAD existentes na Universidade de Franca com o intuito de reelaborar um material instrucional on-line em Língua Portuguesa que fosse capaz de sanar as defasagens dos alunos das engenharias presenciais durante a escrita do Trabalho de Conclusão de Curso. O material on-line elaborado foi composto por três unidades (Coerência-Coesão, Paragrafação e Escrita Acadêmica), contemplou um total de 40 horas e foi disponibilizado via plataforma Blackboard aos 36 alunos do $8^{\circ}$ semestre das Engenharias Mecânica e Mecatrônica 
(presenciais) na disciplina Metodologia Científica (presencial) que estavam na fase inicial de escrita do Trabalho de Conclusão de Curso. Dos 36 alunos matriculados na disciplina presencial, 25 alunos concluíram o Nivelamento on-line. A metodologia ativa abordada foi a de Sala de Aula Invertida (Flipped Classroom) onde os alunos estudavam o conteúdo do nivelamento on-line em casa e os aplicavam durante a aula presencial de Metodologia Científica ministrada no Laboratório de Informática - local em que os alunos pesquisam e escrevem seus TCCs. Tal escolha deve-se ao fato de que, segundo Bacich \& Morán (2015, p. 02), "[...] os alunos desenvolvem habilidades de pensamento crítico e têm uma melhor compreensão conceitual sobre uma ideia quando exploram um domínio primeiro e, a partir disso, têm contato com uma forma clássica de instrução", justificando, assim, a nossa escolha pela sala de aula invertida.

Na segunda fase do Nivelamento On-line em Língua Portuguesa o material on-line foi composto por cinco unidades (Coerência-Coesão, Paragrafação, Escrita Acadêmica, Estratégias de Leitura e Novo Acordo Ortográfico), contemplou um total de 40 horas e foi disponibilizado via plataforma Blackboard aos 102 alunos do $7^{\circ}$ semestre das Engenharias Elétrica, Mecânica e Mecatrônica (todas presenciais) na disciplina Projeto de Pesquisa (presencial) que estavam na fase de elaboração de um Projeto de Pesquisa - fase que antecede a escrita do TCC. Dos 102 alunos matriculados na disciplina presencial, 86 alunos concluíram o Nivelamento on-line. Assim como na primeira fase, a metodologia ativa abordada na segunda fase foi a de Sala de Aula Invertida (Flipped Classroom) pois os alunos estudavam o conteúdo do nivelamento on-line em casa e os aplicavam durante a aula presencial de Projeto de Pesquisa ministrada no Laboratório de Informática - local em que os mesmos pesquisam e desenvolvem seus projetos acadêmicos.

Na terceira fase do Nivelamento On-line em Língua Portuguesa, o material de 40 horas e 5 unidades (Coerência-Coesão, Paragrafação, Escrita Acadêmica, Estratégias de Leitura e Novo Acordo Ortográfico) foi disponibilizado via Blackboard aos alunos de todos os semestres das engenharias Civil e Produção (presenciais) a fim de fomentar um maior conhecimento do funcionamento da Língua Portuguesa nas habilidades de escrita e leitura. Dos cerca de 900 alunos matriculados em todos os semestres, 528 alunos participaram do curso. Nesta fase não houve vínculo do nivelamento a nenhuma disciplina presencial, sendo o curso extracurricular cuja abordagem priorizada foi a de aprendizagem ativa mediada pela tecnologia digital, uma vez que: "Na aprendizagem ativa, em oposição à aprendizagem passiva, bancária, baseada na transmissão de informação, o aluno assume uma postura mais ativa, na qual ele resolve problemas, desenvolve projetos e, com isto, cria oportunidades para a construção de conhecimento (VALENTE, s.d., p.01)". Nesse sentido, as tecnologias digitais propiciam importantes 
mudanças na educação em relação ao processo de ensino/aprendizagem e no papel do professor e aluno promovendo uma aprendizagem ativa e não mais passiva justificando a escolha desta abordagem nesta fase do Nivelamento On-line.

Em sua quarta fase, o Nivelamento On-line em Língua Portuguesa foi oferecido como prática de redação discursiva com 40 horas, 2 unidades (Coerência-Coesão textual e Constituição do Parágrafo), via Blackboard aos alunos do $10^{\circ}$ semestre das Engenharias Elétrica, Mecânica e Mecatrônica (presenciais) que participariam do ENADE 2017. Dos 123 alunos matriculados, 68 finalizaram o curso. Mais uma vez não houve vinculo a nenhuma disciplina presencial, sendo o nivelamento extracurricular priorizando-se, mais uma vez, a aprendizagem ativa mediada pela tecnologia digital dando ao aluno o papel de protagonista no processo de aprendizagem e tirando-o da posição de um mero "recebedor" de informações.

Em todas as quatro fases o ensino híbrido foi utilizado por acreditarmos que "falar em educação híbrida significa partir do pressuposto de que não há uma única forma de aprender e, por consequência, não há uma única forma de ensinar" (BACICH \& MORÁN, 2015, p. 01) e, por meio do uso das tecnologias digitais é possível "propiciar momentos de aprendizagem e troca que ultrapassam as barreiras da sala de aula" (Ibidem, p.01).

Os dados para a análise e discussão dos resultados de todas as quatro fases foram coletados nas produções acadêmicas desenvolvidas pelos alunos e em relatos apresentados como atividade de finalização do Nivelamento On-line em Língua Portuguesa e serão analisados quantitativamente e qualitativamente a seguir.

\section{Apresentação e discussão dos resultados}

Na primeira fase do Nivelamento On-line em Língua Portuguesa, dos 36 alunos, 25 participaram efetivamente de todas as atividades requeridas no curso, sendo elas, a escrita da Introdução do TCC antes do início do curso, a reescrita da Introdução após a conclusão do curso e, por fim, um relato respondendo a seguinte pergunta: Qual o impacto causado pelo conteúdo on-line na escrita de seu TCC? Tanto as introduções quanto os relatos foram utilizados como dados para esta pesquisa. Com os 25 alunos, obteve-se uma participação de 69,4\%, sinalizando o interesse dos alunos das engenharias em cursos que fomentem o conhecimento da Língua Portuguesa, visto que, muitos alunos trazem uma grande defasagem em relação à língua portuguesa desde o 
Ensino Fundamental até o término do Ensino Médio. Segundo dados do INAF (Indicador de Alfabetismo Funcional), "somente $35 \%$ das pessoas com ensino médio completo são classificadas como plenamente alfabetizadas" (INAF, 2012, n.p.).

$\mathrm{Na}$ segunda fase do nivelamento on-line, dos 102 alunos, 86 participaram efetivamente do curso on-line e ao seu término responderam a uma questão aberta: Qual a contribuição do nivelamento on-line na escrita de seu Projeto de Pesquisa? A questão aberta foi utilizada como dados para esta pesquisa. Com os 86 alunos, obteve-se uma participação de $84,3 \%$, mais uma vez sinalizando o interesse dos alunos das engenharias em cursos que fomentem o conhecimento da Língua Portuguesa cabendo às Instituições de Ensino Superior minimizar os impactos existentes entre 0 conhecimento prévio dos alunos ingressantes e as estruturas curriculares dos cursos de graduação. Portanto, muito além do ensino, pesquisa e extensão, é papel da universidade comprometer-se com a realidade a fim de promover transformações culturais, morais e sociais em seus alunos.

No que diz respeito ao impacto do nivelamento on-line nos alunos da primeira fase $\left(8^{\circ}\right.$ semestre da Engenharia Mecânica e Engenharia Mecatrônica), observou-se que houve uma melhora significativa na reescrita da introdução do TCC após a conclusão do curso quanto à coerência, coesão e paragrafação. Esta melhora foi verificada durante a correção da introdução do TCC por parte da professora da disciplina presencial de Metodologia Científica e no relato postado pelos alunos para a finalização do curso. Dos 25 alunos que postaram o relato "Qual o impacto causado pelo conteúdo on-line na escrita do TCC?", 88\% afirmaram que o curso apresentou um impacto positivo na escrita do Trabalho de Conclusão de Curso após a conclusão do curso.

Sobre o impacto do nivelamento on-line nos alunos da segunda fase $\left(7^{\circ}\right.$ semestre da Engenharia Elétrica, Engenharia Mecânica e Engenharia Mecatrônica) observou-se também que houve uma melhora significativa na escrita do Projeto de Pesquisa após a conclusão do curso quanto à coerência, coesão, paragrafação, acentuação, ortografia e estrutura do trabalho acadêmico. Esta melhora foi verificada durante a correção do Projeto de Pesquisa por parte da professora da disciplina presencial de Projeto de Pesquisa e no relato postado pelos alunos para a finalização do curso. Dos 86 alunos que postaram o relato "Qual a contribuição do nivelamento on-line na escrita de seu Projeto de Pesquisa?", 92\% dos alunos relataram que o curso apresentou um impacto positivo na escrita do Projeto de Pesquisa.

Pelas análises acima apresentadas, percebe-se que o ensino híbrido e a sala de aula invertida possibilitaram aos estudantes minimizar os impactos existentes entre 0 
conhecimento prévio da Língua Portuguesa e as exigências curriculares dos cursos de graduação - neste caso, a escrita de um Projeto de Pesquisa e de um Trabalho de Conclusão de Curso - além das exigências do mercado de trabalho (domínio da norma culta e da comunicação escrita) - cumprindo assim a função da Instituição de Ensino Superior.

$\mathrm{Na}$ terceira fase do Nivelamento On-line em Língua Portuguesa, dos cerca de 900 alunos matriculados em todos os semestres, 528 alunos participaram do curso. Com os 528 alunos, obteve-se uma participação de 58,7\%, sinalizando, mais uma vez, o interesse dos alunos das engenharias em cursos que fomentem o conhecimento da Língua Portuguesa. Nesta fase não houve vínculo do nivelamento a nenhuma disciplina presencial, sendo o curso, extracurricular. Como forma de coleta de dados, foi solicitado aos alunos que enviassem, voluntariamente, ao término do curso, um relato sobre motivação: "O que o/a motivou a fazer o curso Nivelamento On-Line em Língua Portuguesa?". Dos alunos concluintes, 60 deles postaram seus relatos voluntariamente e serão apresentados os discursos recorrentes encontrados nos relatos sobre motivação. Por ser uma questão aberta, cada aluno apresentou mais de uma razão para ter realizado o curso, sendo elas: - A motivação veio da necessidade de "aprimorar", "melhorar", "renovar", "atualizar", "ampliar" e "aprofundar" os conhecimentos em Língua Portuguesa; - de "testar" o conhecimento em Língua Portuguesa"; - do "pouco conhecimento da Língua Portuguesa"; - do desejo de "melhorar o desempenho na graduação como um todo"; - da "importância da comunicação oral e escrita exigida pelo mercado de trabalho"; - da necessidade do "domínio da comunicação escrita nos relatórios técnicos, avaliações e TCCs"; - do "pouco estudo de comunicação ou Língua Portuguesa nos cursos de Engenharia"; - pelo fato do curso ser oferecido "a distância".

Observa-se que alguns alunos consideram ter um domínio prévio da língua em questão, mas que o mesmo pode ser melhorado e até mesmo testado. Fica claro que os alunos reconhecem a importância da Língua Portuguesa como responsável pelas principais intermediações profissionais e acadêmicas e que esta pode inviabilizar a permanência na vida acadêmica e no mercado de trabalho (discurso da exclusão). Identifica-se também o discurso da autonomia de tempo e espaço, da dimensão temporal da assincronicidade, da possibilidade de inclusão social, da democratização do ensino, da formação continuada - principais características do ensino à distância.

Desta forma, compartilhamos as idéias de Martha Gabriel (2016 apud TECEDUC, 2016, n.p.) a respeito da aprendizagem ativa mediada pela tecnologia digital: "[...] o estudante se coloca no centro da educação, passando de um recipiente passivo para um agente empoderado. [...] Assim, a característica que os ambientes digitais oferecem de 
centralizar a aprendizagem nos estudantes possibilita transformações efetivas, não apenas na cognição, mas na atitude e responsabilidade compartilhada em relação a ela".

$\mathrm{Na}$ quarta fase, dos 123 alunos matriculados, 68 realizaram o curso. Com os 68 alunos, obteve-se uma participação de 55,3\%, sinalizando, novamente, o interesse dos alunos das engenharias em cursos que promovam o conhecimento da Língua Portuguesa. Mais uma vez não houve vinculo a nenhuma disciplina presencial, sendo o nivelamento extracurricular cuja abordagem adotada, foi a de aprendizagem ativa. Como forma de coleta de dados para esta pesquisa os alunos foram convidados a postar voluntariamente as redações dissertativas que fizeram em uma Prova Integrada no primeiro semestre de 2017 com o seguinte tema: "Redija um texto dissertativo sobre o impacto da Lei Maria da Penha no quadro de violência contra a mulher no Brasil" (tema presente no ENADE 2016). Posteriormente, ao encerrarem o curso, os mesmos alunos voluntários foram convidados a dissertarem novamente sobre a mesma questão (Maria da Penha) que será avaliada segundo os mesmos critérios de correção. As redações realizadas pelos alunos encontram-se em análise e os resultados obtidos serão apresentados em artigo futuro.

Sobre o uso da tecnologia digital, em todas as quatro fases, não houve treinamento aos alunos, pois os mesmos já estavam habituados à Plataforma Blackboard - utilizada como ambiente virtual de aprendizagem de apoio às disciplinas presenciais. Os alunos foram orientados para que as dúvidas sobre o funcionamento do curso on-line fossem discutidas nas aulas presenciais (primeira e segunda fase) e via Fórum de Discussão (terceira e quarta fase), porém, em nenhum momento aluno algum apresentou dúvidas sobre o uso da tecnologia envolvida ou da utilização do material on-line.

Portanto, o índice de participação nas quatro fases (69,4\%, 84,3\%, 58,7 e 55,3\%, respectivamente), bem como, a ausência de treinamento ou tutoria, corrobora com o fato dos alunos participantes serem "nativos digitais".

Para Prensky (2001, p.01), os “estudantes de hoje são todos 'falantes nativos' da linguagem digital dos computadores, vídeo games e internet" e, portanto, "pensam e processam as informações bem diferentes das gerações anteriores".

A partir desta experiência pedagogia, verificou-se que é possível desenvolver material instrucional a distância em Língua Portuguesa capaz de sanar as necessidades específicas dos alunos das engenharias presenciais com uma aprendizagem mais flexível e personalizada. É o ensino híbrido colaborando com a aprendizagem no ensino 
presencial.

\section{Considerações Finais}

Observou-se que todos os objetivos do Nivelamento On-line em Língua Portuguesa puderam ser cumpridos em virtude das metodologias ativas (sala de aula invertida) e do ensino híbrido aplicado ao ensino superior.

Também verificou-se que foi possível minimizar os impactos existentes entre o conhecimento prévio da Língua Portuguesa dos alunos em relação às exigências curriculares dos cursos de Engenharia e do mercado de trabalho graças ao ensino híbrido, sem o qual poderia ter sido impossível devido aos compromissos profissionais (estágios e empregos) e acadêmicos dos alunos envolvidos.

Além disso, constatou-se também que o nivelamento oferecido de forma on-line atingiu a maior parte dos alunos ingressantes por serem "nativos digitais" que, de acordo com Prensky (2001), comunicam-se e compartilham o saber mais rapidamente por intermédio das tecnologias.

Percebe-se que a utilização das metodologias ativas via ensino híbrido pode favorecer a aprendizagem do aluno nas questões referentes ás suas defasagens, não apenas na Língua Portuguesa, responsável pelas principais intermediações acadêmicas, profissionais, sociais e pessoais, mas em diversas áreas do saber.

Finalizamos nossas considerações com as idéias de Bacich \& Morán (2015, p.01), as quais "a integração cada vez maior entre sala de aula e ambientes virtuais é fundamental para abrir a escola para o mundo e trazer o mundo para dentro da escola".

\section{Referências}

BACICH, Lilian; MORÁN, José. Aprender e ensinar com foco na educação híbrida. Revista Pátio, oㅡ 25, junho, 2015, p. 45-47. Disponível em: <http://www.grupoa.com.br/r evistapatio/artigo/11551/aprender-e-ensinar-com-foco-na-educacao-hibrida.aspx>. Acesso em: 05 abr. 2018. 
INAF. Instituto Paulo Montenegro e Ação Educativa mostram evolução do alfabetismo funcional na última década. 2012. Disponível em: <http://www.ipm.org.br/ ptbr/programas/inaf/relatoriosinafbrasil/Paginas/inaf2011_2012.aspx>. Acesso em: 20 abr. 2018.

MEC - Ministério da Educação e Cultura. Instruções para elaboração de plano de desenvolvimento institucional. 2006.2 Disponível em: <http://www2.mec.gov.br/sapiens/pdi.html>. Acesso em: 02 mar. 2018.

MORÁN, José. Mudando a educação com metodologias ativas. Coleção Mídias Contemporâneas. Convergências Midiáticas, Educação e Cidadania: aproximações jovens. Vol. II. PG: Foca Foto-PROEX/UEPG, 2015.

PRENSKY, M. Digital natives, digital immigrants. On the Horizon, v 9, n. 5. MCB University Press. Out. 2001. Disponível em: <http://www.marcprensky.com/writing/Prens ky\%20\%20Digital\%20Natives,\%20Digital\%20Immigrants\%20-\%20Part1.pdf>. Acesso em: 15 mar. 2018.

TECEDUC. Martha Gabriel aborda relação da aprendizagem ativa com a tecnologia. 2016. Disponível em: < http://www.positivoteceduc.com.br/em-pauta/marthagabriel-aborda-aprendizagem-ativa-e-tecnologia/>. Acesso em: 05 maio 2018.

VALENTE, José Armando. Blended learning e as mudanças no Ensino Superior: a proposta da sala de aula invertida. Educar em Revista, Curitiba, Edição Especial, n. 4, p. 79-97, 2014.

Aprendizagem Ativa no Ensino Superior: a proposta da sala de aula invertida. [s.d.]. Disponível em: <http://www.pucsp.br/sites/default/files/img/aci/27-8_agur dar_proec_textopara280814.pdf >. Acesso em: 12 abr. 2018. 